\title{
Pelaksanaan program pembelajaran pengembangan komunikasi persepsi bunyi dan irama tahap identifikasi siswa tunarungu kelas
}

\author{
Mila Ayu Setyaningsih, Rafika Rahmawati \\ Pendidikan Luar Biasa, Fakultas Ilmu Pendidikan, Universitas Negeri Yogyakarta. Jalan Colombo \\ No.1, Yogyakarta, 55281, Indonesia \\ Corresponding Author. E-mail: mila.ayu@student.uny.ac.id
}

\begin{abstract}
Abstrak: Penelitian ini bertujuan untuk mendeskripsikan pelaksanaan program pendidikan PKPBI (Pengembangan Komunikasi Persepsi Bunyi dan Irama) tentang tahap identifikasi bunyi pada kelas 1 di SLB N 1 Bantul. Jenis penelitian ini adalah penelitian deskriptif kualitatif. Subjek dalam penelitian ini adalah guru mata pelajaran PKPBI dan siswa tunarungu kelas 1 di SLB N 1 Bantul yang berjumlah 7 orang siswa. Metode yang digunakan dalam pengumpulan data adalah observasi, wawancara, dan dokumentasi. Tehnik yang digunakan untuk menganalisis data adalah tehnik analisis deskriptif. Hasil penelitian menunjukkan bahwa dalam pelaksanaan program pendidikan PKPBI kelas 1 sudah sesuai dengan komponen pendidikan, yang pertama tujuan pendidikan yaitu dalam pelaksanaan pembelajaran guru menggunakan pedoman kurikulum 2013, membuat perencanaan, pelaknasaan pendidikan meliputi kegiatan pendahuluan, inti dan penutup. Metode yang digunakan guru adalah sosial activity, bermain peran, percakapan, dan demonstrasi. Kegiatan evaluasi yang digunakan adalah kegiatan evaluasi formatif. Kedua yaitu peserta didik, dalam penelitian ini peserta didik yang diteliti adalah anak tunarungu dengan kategori masih memiliki sisa pendengaran dan dalam pelaksanaan pembelajaran adalah student center atau pendidikan berpusat pada peserta didik. Ketiga yaitu pendidik yang sudah berpengalaman mendidik anak tunarungu. Keempat yaitu media, media yang digunakan dalam pembelajaran PKPBI tahap identifikasi kelas 1 adalah sarana fisik dan perlengkapan pembelajaran berupa alat non elektronik.
\end{abstract}

Kata Kunci: pembelajaran PKPBI, anak tunarungu

\section{Implementation of learning program for communication development of sound perception and rythm on the identification stage of deaf students class 1}

\begin{abstract}
This study aims to describe the implementation of learning programs for Communication Development of Sound Perception and Rhythm (PKPBI), especially on the identification stage of sound in class 1 in SLB N 1 Bantul. The type of this research is descriptive research. Subjects in this study were teachers PKPBI and 7 deaf students in grade 1 in SLB N 1 Bantul. The methods used in data collection were observation, interview, and documentation. The technique used to analyze the data was descriptive analysis technique. The result of the research shows that the implementation of educational program PKPBI grade 1 is in accordance with the educational component, first educational goal which is the learning implementation teacher uses curriculum guidance of 2013, making planning, educational implementation involve activityof intriduction, subject matter, condution. The teacher uses social activity, role play, conversation, and demonstations mettods. Evaluation activity used is formatife evaluation activity. Second, student the subject of this research is deef student in categories stil has residual hearing and in the learning implementation is student center or education centered on student. Third, experienced teacher teach the deaf student. Fhourth, media used in learning PKPBI identification step grade 1 are physical fecilities and learning equipments in the from of non electric equipments.
\end{abstract}

Keywords: PKPBI learning, deaf children

\section{PENDAHULUAN}

Anak tunarungu adalah anak yang mengalami hambatan dalam pendengaran. Anak tunarungu menurut Winarsih (2007:22) adalah "istilah yang menunjukkan kesulitan mendengar dari yang ringan sampai berat yang digolongkan menjadi tuli dan kurang dengar”. Optimalisasi fungsi pendengaran anak tunarungu diperlukan, dengan cara dilatih untuk menangkap pembicaraan orang lain atau lawan bicara melalui gerak bibir dan indra penglihatan. Program Pengembangan Komunikasi Persepsi Bunyi 
dan Irama (PKPBI) merupakan salah satu program pembelajaran untuk memaksimalkan fungi pendengaran anak tunarungu.

PKPBI merupakan latihan memahami bunyi agar sisa-sisa pendengaran anak tunarungu dapat dimaksimalkan perkembangan bahasa dan bicara. Menurut Purbaningrum (2006:3) Bina Komunikasi Persepsi Bunyi dan Irama adalah "pembinaan dalam menghayati bunyi yang dilakukan secara sistematis dengan sengaja atau tidak sengaja sehingga sisa pendengara dan perasaan vibrasi anak tunarungu dapat digunakan sebaik-baiknya untuk berinteraksi dengan lingkungan”. Tahapan dalam melakukan pembelajaran BKPBI adalah sebagai berikut; (1) Tahapan deteksi bunyi, (2) Tahap deskriminasi bunyi, (3) Tahap identifikasi bunyi, (4) Tahap komprehensi. Penelitian ini pada tahap identifikasi bunyi. Berdasarkan Kemendikbud dalam pelatihan program pendidikan khusus (2016:17) indikator dalam pembelajaran PKPBI tahap Identifikasi mencakup mengenal bunyi, mengucapkan kembali bunyi, menunjukkan tulisan, menuliskan, dan membaca kembali apa yang ditulis oleh peserta didik.

Jenis Penelitian

\section{METODE PENELITIAN}

Penelitian ini menggunakan metode penelitian kualitatif dengan jenis penelitian deskriptif. Metode pengumpulan data yang digunakan yaitu observasi, wawancara, dandokumentasi. Analisis data yang digunakan menggunakan analisis deskriptif kualitatif.

\section{Waktu dan Tempat Penelitian}

Penelitian ini dilaksanakan di SLB N 1 Bantul yang beralamat di Jalan Wates KM 3. No 147 Ngestiharjo, Kasihan, Bantul. Penelitian ini dilaksanakan pada semester delapan pada bulan Februari 2018-Maret 2018.

Subjek Penelitian

Subjek dalam penelitian ini adalah seorang guru mata pelajaran PKPBI dan siswa kelas 1 yang berjumlah 7 siswa, terdiri dari 6 siswa perempuan dan 1 siswa laki-laki.

\section{Data, Instrumen, dan Teknik Pengumpulan Data}

Pengumpulan data merupakan cara untuk memperoleh informasi dalam penelitian. Pengumpulan data menurut Suharsaputra (2012:207) "merupakan serangkaian proses yang dilakukan sesuai dengan metode penelitian yang dipergunakan". Tehnik pengumpulan data yang digunakan dalam penelitian ini adalah observasi, wawancara, dan dokumentasi. Instrumen penelitian menurut Arikunto (2002:136) 'instrumen adalah alat atau fasilitas yang digunakan oleh peneliti dalam mengumpulkan data agar pekerjaannya lebih mudah dan hasilnya lebih baik, dalam arti lebih cermat, lengkap dan sistematis sehingga mudah diolah” Instrumen yang digunakan yaitu instrumen wawancara da instrumen observasi.

\section{Teknik Analisis Data}

Analisis yang digunakan dalam penelitian ini adalah deskriptif kualitatif. Menurut Agustinova (2015:61) “Analisis data adalah proses pengorganisasian dan mengurutkan data kedalam pola, kategori dan satuan uraian dasar sehingga dapat ditemukan tema dan dapat dirumuskan hipotesis".

Dalam penelitian ini menggunakan model analisis Miles dan Huberman. Miles dan Huberman dalam (Agustinova 2015:63) mengemukakan bahwa " analisis data kualitatif dilakukan secara interaktif dan berlangsung secara terus menerus sampai tuntas sehingga datanya jenuh”. Data jenuh yang dimaksudkan yaitu ditandai dengan tidak adanya data atau informasi baru. Langkah-langkah analisis meliputi reduksi data, penyajian data, serta penarikan kesimpulan.

\section{HASIL PENELITIAN DAN PEMBAHASAN}

\section{A. Hasil Penelitian}

1. Tujuan Program Pembelajaran PKPBI

Tujuan pelaksanaan program pembelajaran PKPBI pada tahap identifikasi bunyi adalah agar peserta didik mampu menemu kenali bahwa bunyi atau suara yang peserta didik dengar mempunyai makna dalam kehidupan. Materi program pembelajaran PKPBI kelas 1 tahap identifikasi bunyi adalah mengetahui kata sehari-hari yang dilakukan orang dengar pada umunya. Pada pembelajaran tahap identifikasi bunyi peserta didik diharapkan mampu untuk :

a) Mengenal bunyi benda sebagai sinyal yang diperdengarkan secara langsung. 


\section{J PK (J urnal Pendidikan Khusus), 14 (1), 2018 - 20}

Mila Ayu Setyaningsih, Rafika Rahmawati

b) Mengucapkan kembali bunyi benda sebagai sinyal

c) Bergerak bila mendengar bunyi benda sebagai sinyal

d) Menunjukkan tulisan bunyi benda sebagai sinyal.

e) Memainkan sumber bunyi bila mendengar bunyi benda sebagai sinyal

f) Bermain peran bila mendengar bunyi benda sebagai sinyal.

Setiap penyelenggaraan suatu program pendidikan terdapat kurikulum yang digunakan sebagai rencana dalam pelaksanaan pembelajaran. Kurikulum yang digunakan oleh guru dalam program pembelajaran PKPBI yaitu kurikulum 2013 revisi. Dalam pelaksanaannya guru tidak memodifikasi kurikulum atau mengembangkan kurikulum karena kurikulum yang digunakan sudah menggunakan kurikulum 2013 pendidikan khusus.

Sebelum melaksanakan suatu kegiatan pembelajaran perencanaan. Dalam kegiatan program pembelajaran PKPBI hal yang menjadi perencanaan yaitu berkaitan dengan persiapan guru sebelum pembelajaran dan administrasi yang digunakan sebelum pelaksanaan program pembelajaran PKPBI. Persiapan yang dilakukan guru sebelum pembelajaran PKPBI pada tahun ajaran baru yaitu guru melihat program PKPBI dari setiap jenjang kelas, dan melihat hasil asesmen pada awal tahun ajaran, serta asesmen akademik program khusus guna mengetahui materi pembelajaran PKPBI yang akan diberikan sehingga dapat merumuskan tujuan pelaksanaan sesuai dengan kemampuan awal peserta didik. Guru juga membuat administrasi sebelum melakukan kegiatan pembelajaran. Administrasi pembelajaran yang dibuat guru yaitu Rencana Pelaksanaan Pembelajaran (RPP).

Tahap pelaksanaan program pembelajaran PKPBI kelas 1 tahap identifikasi terbagi menjadi tiga tahap yaitu kegiatan pendahuluan kegiatan inti dan kegiatan penutup. Kegiatan pendahuluan yang dilakukan guru yaitu dengan cara mengkondisikan peserta didik untuk siap menerima pembelajaran PKPBI. Tahap inti dilakukan dengan menyampaikan materi dan penilaian. Kegiatan penutup dilakukan dengan mengkondisikan peserta didik untuk mengakhiri kegiatan pembelajaran.

Metode dan media yang digunakan guru dalam kegiatan program pembelajaran PKPBI adalah Metode sosial activity yaitu metode yang memperdayakan peserta didik agar belajar menggunakan berbagai cara secara aktif. Metode bermain peran yaitu salah satu bentuk permainan pendidikan yang digunakan untuk menjelaskan materi. Metode percakapan yaitu metode yang dilakukan dengan cara bercakap antara guru dengan peserta didik. Metode demonstrasi yaitu metode pembelajaran dengan memperagakan atau mempertunjukkan untuk memperjelas materi.

Pelaksanaan evaluasi program pembelajaran PKPBI tahap identifikasi kelas 1 di SLB N 1 Bantul menggunaka jenis evaluasi formatif. Tehnik yang digunakan yaitu evaluasi proses setiap kegiatan pembelajaran. Evaluasi formatif dilaukan secara langsung dalam proses pembelajran yang dilakukan setiap pertemuan dalam pembelajaran PKPBI tahap identifikasi kelas 1 yang bersifat autentik dan tidak menggunakan rubik penilaian, sehingga nilai yang diberikan berupa deskriptif.

2. Peserta Didik

Penelitian ini peserta didik yang diteliti adalah peserta didik anak tunarungu kelas 1 yang dikategorikan masih memiliki sisa pendengaran. Peserta didik yang diteliti adalah siswa kelas 1 yag berjumlah 7 siswa terdiri dari enam putri dan satu putra yang dikategorikan masih memiliki sisa pendengaran. Karakteristik yang dimiliki dari segi intlegensi sama dengan anak normal anak tidak mengalami hambatan dalam penglihatan dan motorik, yang mengalami hambatan hanya yang bersifat verbal. Ketrampilan bahasa siswa yaitu kosakata yang dimiliki sedikit, sulit memahami kalimat abstrak serta kurang memahami irama dan gerak. Dilihat dari karakteristik emosi dan sosial siswa kelas 1 memiliki ego dan cenderung ingin benar dalam pembelajaran PKPBI.

3. Tenaga Pendidik

Tenaga pendidik mata pelajaran PKPBI atau guru khusus untuk mengajar mata pelajaran PKPBI. guru merupakan lulusan dari SGPLB Bandung beliau mengajar mata pelajaran PKPBI hingga jenjang SMP. Beliau mengajar mata pelajaran PKPBI sejak tahun 1983 yang dahulu bernama Bina Gerak Bunyi dan Irama, pada tahun 1994 namanya ganti menjadi Bina Komunikasi Persepsi Bunyi dan Irama, dan pada tahun 2015 namanya ganti menjadi Pegembangan Komunikasi persepsi Bunyi dan Irama hingga sekarang, jadi beliau sudah mengajar mata pelajaran PKPBI selama 35 tahun yang sudah berganti nama sebanyak tiga kali. Beliau mendapat kemampuan mengajar PKPBI yaitu dari mengikuti pelatihan di SLB Santirama jakarta dan sering mengikuti pelatihan-pelatihan, selain itu 
beliau juga membaca buku-buku terkait PKPBI. Riwayat beliau dapat mengajar di SLB N 1 Bantul yaitu beliau adalah guru yang mendapat tugas tambahan sebagai kepala sekolah di salah satu SLB di Yogyakarta namun pada tahun 2015 tugas tambahan tersebut berakhir, sehingga beliau di tempatkan di SLB N 1 Bantul sebagai guru mata pelajaran PKPBI.

4. Media Pembelajaran PKPBI Tahap Identifikasi

Media merupakan alat yang digunakan untuk membatu dalam pelaksanaan penyampaian materi pembelajaran. Media yang digunakan dalam pembelajaran PKPBI tahap identifikasi yaitu tambur, tambur adalah alat musik yang berbentuk bulat, cara menggunakannya di tabuh, yang digunakan untuk mengidentifikasi suku kata. Cara menggunakan tambur yaitu sebagai berikut:

a) Guru dan peserta didik bercakap untuk menentukan kata yang akan diidentifikasi

b) Setelah mendapat satu kata misal kata "sakit", peserta didik membaca menggunakan irama dan mengidentifikasi setiap suku kata menggunakan tambur menjadi sa-kit

c) Irama diidentifikasi menggunakan alat musik, irama yang di baca panjang-pendek, dan keras-pelan.

5. Hasil kemampuan identifikasi bunyi

kelas 1

Berdasarkan hasil observasi yang telah dilakukan kemampuan mengidentifikasi peserta didik

kelas 1.

Berikut merupakan hasil observasi kemampuan mengidentifikas bunyi peserta didik kelas 1 yang dapat di lihat pada tabel 1.

Tabel 1. Data kemampuan identifikasi bunyi mata pelajaran PKPBI kelas 1

\begin{tabular}{|c|c|c|c|c|c|c|c|}
\hline \multirow{2}{*}{ No. } & \multirow{2}{*}{ Subjek } & \multicolumn{6}{|c|}{ Materi } \\
\hline & & 1 & 2 & 3 & 4 & 5 & 6 \\
\hline 1. & SF & Baik & Baik & Baik & Baik & Baik & Cukup \\
\hline 2. & FL & Cukup & Baik & Baik & Baik & Baik & Cukup \\
\hline 3. & SI & Baik & Baik & Baik & Baik & Baik & Cukup \\
\hline 4. & RY & Baik & Baik & Baik & Baik & Cukup & Baik \\
\hline 5. & $\mathrm{AD}$ & Cukup & Baik & Baik & Baik & Baik & Baik \\
\hline 6. & UL & Baik & Baik & Baik & Baik & Baik & Cukup \\
\hline 7. & RS & Baik & Baik & Cukup & Baik & Cukup & Baik \\
\hline
\end{tabular}

\section{Keterangan :}

Baik : : Mampu melaksanakan perintah dengan benar

Cukup : Mampu melaksanakan perintah dengan bantuan

Kurang : Tidak mampu melaksanakan perintah

\section{Keterangan Materi :}

1. Menirukan ucapan guru

2. Menunjukkan tulisan dengan mengucapkan ucapan guru

3. Menunjukkan tulisan dengan gambar

4. Mencari tulisan yang diperlihatkan guru dari beberapa bias kata

5. Menuliskan apa yang diucapkan guru

6. Membaca apa yang ditulis

Berdasarkan tabel di atas maka dapat dilihat kemampuan peserta didik dalam mengidentifikasi bunyi. Pada materi menirukan ucapan guru terdapat 5 peserta didik mampu menirukan apa yang diucapkan guru dan 2 peserta didik mampu menirukan ucapan guru namun dengan bantuan.

Pada materi menunjukkan tulisan dengan mengucapkan ucapan guru semua peserta didik mampu menunjukkan tulisan dengan benar dan mengucapkan ucapan guru dengan benar. Materi menunjukkan tulisan dengan gambar terdapat enam peserta didik menjawab dengan benar dan 1 peserta didik menjawab dengan bantuan. 6 peserta didik mampu menunujukan gambar yang sesuai dengan kata yang diucapkan guru dan terdapat 1 peserta didik kurang tepat saat menunjukkan gambar dengan tulisan atau gambar dengan ucapan guru.

Materi mencari tulisan yang diperlihatkan guru dari beberapa bias kata, semua peserta didik 
mampu untuk mengidentifikasi tulisan yang diperlihatkan guru. Guru memperlihatkan kata atau kalimat dan peserta didik dimita satu pesatu untuk mengidentifikasi. Pada materi menulis apa yang diucapkan guru terdapat 5 peserta didik mampu menulis dengan benar dan 2 peserta didik menulis memerlukan bantuan guru, karena peserta didik menulis terdapat huruf yang kurang tepat sehingga guru memberi koreksi kepada peserta didik. Pada materi membaca apa yang ditulis oleh peserta didik di buku tugas terdapat 4 siswa membaca kurang tepat pada pelafalannya dan membutuhkan bimbingan guru serta 3 peserta didik mampu membaca dengan benar.

\section{B. Pembahasan}

Optimalisasi fungsi pendengaran anak tunarungu diperlukan, dengan cara dilatih untuk menangkap pembicaraan orang lain atau lawan bicara melalui gerak bibir dan indra penglihatan. Pembelajaran PKPBI perlu diberikan kepada peserta didik tunarungu sedini mungkin, agar kemampuan mendengar dan mempersepsi bunyi dapat dimaksimalkan. Pengembangan Komunikasi Persepsi Bunyi dan Irama merupakan latihan memahami bunyi agar sisa-sisa pendengaran anak tunarungu dapat dimaksimalkan perkembangan bahasa dan bicara.

Tujuan program Pengembangan Komunikasi Persepsi Bunyi dan Irama yaitu untuk mengoptimalkan kemampuan peserta didik dalam berbahasa melalui rangsangan bunyi. Tujuan ini sesuai dengan tujuan menurut Winarsih (2007:83) yaitu agar anak tunarungu dapat terhindar dari cara hidup yang semata-mata tergantung pada daya penglihatan saja, sehingga cara hidupnya lebih mendekatai anak normal.

Di SLB N 1 Bantul program PKPBI sudah menjadi mata pelajaran bagi peserta didik tunarungu pelaksanannya dilakukan satu kali pertemuan dalam seminggu. Pembelajaran PKPBI di kelas 1 saat ini pada tahap Identifikasi Bunyi. Sebelum dilakukan proses pembelajaran perlu dilakukan suatu perencanaan yang dapat digunakan sebagai persiapan apa yang harus dilakukan dan disiapkan untuk mencapai tujuan pembelajaran yang sudah ditetapkan

Perencanaan yang dilakukan oleh guru sebelum pembelajaran PKPBI kelas 1 tahap identifikasi di SLB N 1 Bantul yaitu guru merumuskan tujuan pembelajaran sesuai dengan kemampuan awal peserta didik yang dilakukan dengan cara guru melihat program PKPBI dari setiap jenjang kelas, dan melihat hasil asesmen awal serta hasil asesmen akademik program khusus. Guru belum melakukan asesmen kemampuan mendengar dan mengobservasi secara khusus untuk setiap peserta didik untuk mengetaui program yang sesuai. Perencanaan program yang dilakukan guru masih bersifat klasikal yaitu menentukan tujuan secara umum dalam menentukan tujuan dalam materi pembelajaran PKPBI. Guru juga membuat administrasi sebelum melakukan kegiatan pembelajaran. Administrasi yang dibuat guru yaitu Rencana Pelaksanaan Pembelajaran (RPP).

Dari uraian tersebut dapat diketahui dalam pelaksanaan pembelajaran PKPBI kelas 1 tahap identifikasi sudah memenuhi beberapa kriteria perencanaan. Seperti yang telah dikemukakan oleh Majid (2006:17) bahwa "perencanaan merupakan proses menyusun materi pembelajaran, penggunaan media pembelajaran, pengguaan metode pembelajaran dan penilaian untuk mencapai tujuan yang ditetapkan”. Guru telah merencanakan pembelajaran PKPBI dengan memenui beberapa poin yang ada pada tahap tersebut.

Pelaksanaan program pembelajaran PKPBI kelas 1 di SLB N 1 Bantul sudah mencapai tahap Identifikasi Bunyi. Peserta didik sudah melalui tahap deteksi bunyi, dan tahap diskriminasi bunyi. Hal ini sesuai dengan yang di jelaskan oleh Wasita (2012:42) bahwa "Tahap pelaksanaan PKPBI meliputi tahap deteksi bunyi, tahap diskriminasi bunyi, tahap identifikasi bunyi, dan komperhensi”. Hermanto (2010:13) juga menyatakan bahwa "melalui pembelajaran PKPBI yang dilakukan secara bertahap tentu akan meningkatkan kemampuan pendengaran peserta didik tunarungu menjadi semakin baik". Seperti pembelajaran pada umumnya, pelaksanaan pembelajaran PKPBI kelas 1 tahap identifikasi di SLB N 1 Bantul terbagi menjadi tiga tahap dalam pembelajaran yaitu kegiatan awal, kegiatan inti, dan kegiatan akhir. Hal ini sesuai dengan pendapat Yaumi (2014:242) yang mengatakan bahwa “ Aktivitas pembelajaran dimulai dari kegiatan pendahuluan, kegiatan inti, dan kegiatan penutup”.

Metode yang dilakukan guru dalam pelaksanaan program pembelajaran PKPBI kelas 1 tahap identifikasi bunyi adalah metode sosial activity, bermain, percakapan, dam demonstrasi. Hal ini juga dijelaskan oleh Wasita (2012:43) bahwa "metode yang digunakan dalam pelaksanaan pembelajaran PKPBI diantarannya adalah metode bermain, pemberian tugas, demonstrasi, dan observasi”. 


\section{J PK (J urnal Pendidikan Khusus), 14 (1), 2018 - 23}

Mila Ayu Setyaningsih, Rafika Rahmawati

Evaluasi pelaksanaan program pembelajaran PKPBI kelas 1 tahap identifikasi di SLB N 1 Bantul menggunakan jenis evaluasi formatif. Tujuan dari evaluasi tersebut yaitu untuk megetahui dan mengevaluasi apakah program yang diberikan sudah dikuasai peserta didik atau belum. Evaluasi formatif merupakan evaluasi langsung dalam proses pembelajran. Hal ini sesuai dengan pernyataan Amironto \& Daryanto (2013:55) menjelaskan bahwa evaluasi formatif adalah "Evaluasi yang dilakukan pada akhir program pembelajaran yang digunakan untuk mengetahui tingkat keberhasilan dan meningkatkan proses belajar mengajar”. Evaluasi yang dilakukan dalam pembelajaran PKPBI tahap identifikasi kelas 1 dalam satu pertemuan dilakukan secara individual. Nilai yang diberikan bersifat autentik atau mengukur kinerja peserta didik pada aktifitas yang relevan pada saat pembelajaran dan tidak menggunakan rubik penilaian. Jenjang pendidikan kelas 1 tidak mengunakan tes akhir semester yang dilakukan secara khusus, jadi nilai yang diperoleh dalam raport melalui kegiatan proses dalam evaluasi formatif.

Tenaga pendidik mata pelajaran PKPBI sudah perpengalaman mengajar mata pelajaran PKPBI selama 35 tahun, sehingga guru dinilai mampu dan berkompetensi dalam mengajar mata pelajaran PKPBI. Dari pengalaman tersebut guru sudah memenuhi persyaratan sebagai guru anak tunarungu menurut Yuwati (2000:26) yaitu memiliki pengalaman sekurang-kurangnya dua tahun yang diharapkan mampu memilih metode yang sesuai untuk anak tunarungu, menguasai seluruh program pendidikan anak tunarungu dan sudah terbiasa bergaul dengan anak tunarungu”.

Penggunaan media dalam pelaksanaan program pembelajaran PKPBI kelas 1 tahap Identifikasi disesuaikan dengan tujuan dan materi yang diidentifikasi. Media yang digunakan dalam latihan mengidentifikasi adalah tabur. Yuwati (2000: 28) menyebutkan perlengkapan dalam melaksanakan Pengembangan Komunikasi Persepsi Bunyi dan Irama yaitu: "Perlengkapan nonelektronik (lonceng, drum, kentongan, dll) dan perlengkapan elektronik (seperti tape recorder), serta alat-alat penunjang yaitu perlengkapan bermain (seperti kuda lumping, boneka, dll)”. Media yang berupa sumber bunyi dimanfaatkan guru sesuai dengan fungsinya dan sesuai dengan materi dan tujuan. Guru memilih menggunakan tambur karena media ini mudah digunakan untuk membatu mengidentifikasi bunyi.

Berdasarkan hasil observasi, wawancara, dan dokumentasi proses pembelajaran PKPBI tahap identifikasi kelas 1 dapat dikatakan semua peserta didik dapat mengikuti kegiatan pembelajaran dengan baik. Sebagian besar peserta didik mampu memahami materi pembelajaran dengan baik, namun masih ada beberapa siswa yang mengalami kesulitan dalam mengikuti pembelajaran. Kesulitan yang dialami siswa yaitu siswa kesulitan dalam mengucapkan kata dengan benar.

\section{SIMPULAN}

\section{Kesimpulan}

Berdasarkan hasil penelitian dan pembahasan secara keseluruhan tentang pelaksanaan program pembelajaran Pengembangan Komunikasi Persepsi Bunyi dan Irama maka dapat ditarik kesimpulan sebagai berikut.

1. Tujuan program Pengembangan Komunikasi Persepsi Bunyi dan Irama yaitu untuk mengoptimalkan kemampuan peserta didik dalam berbahasa melalui rangsangan bunyi. Kurikulum yang digunakan oleh guru dalam program pembelajaran PKPBI yaitu kurikulum 2013 revisi. Dalam pelaksanaannya guru tidak memodifikasi kurikulum atau mengembangkan kurikulum karena kurikulum yang digunakan sudah menggunakan kurikulum 2013 pendidikan khusus. Sebelum dilakukan proses pembelajaran perlu dilakukan suatu perencanaan yang dapat digunakan sebagai persiapan apa yang harus dilakukan dan disiapkan untuk mencapai tujuan pembelajaran. Perencanaan yang dilakukan oleh guru sebelum pembelajaran PKPBI kelas 1 tahap identifikasi di SLB N 1 Bantul yaitu guru merumuskan tujuan pembelajaran sesuai dengan kemampuan awal peserta didik yang dilakukan dengan cara guru melihat program PKPBI dari setiap jenjang kelas, dan melihat hasil asesmen awal serta hasil asesmen akademik program khusus dan RPP. Pelaksanaan pendidikan PKPBI kelas 1 tahap identifikasi di SLB N 1 Bantul terbagi menjadi tiga tahap dalam pembelajaran yaitu kegiatan awal, kegiatan inti, dan kegiatan akhir. Metode yang dilakukan guru dalam pelaksanaan program pembelajaran PKPBI kelas 1 tahap identifikasi bunyi adalah metode sosial activity, bermain, percakapan, dam demonstrasi. Evaluasi pelaksanaan program pembelajaran PKPBI kelas 1 tahap identifikasi di SLB N 1 Bantul menggunakan jenis 


\section{J PK (J urnal Pendidikan Khusus), 14 (1), 2018 - 24}

Mila Ayu Setyaningsih, Rafika Rahmawati

evaluasi formatif. Evaluasi yang dilakukan dalam pembelajaran PKPBI tahap identifikasi kelas 1 dalam satu pertemuan dilakukan secara individual yaitu peserta dinilai kemampuan mengidentifikasi bunyi satu persatu. Nilai yang diberikan bersifat autentik atau mengukur kinerja peserta didik pada aktifitas yang relevan pada saat pembelajaran dan tidak menggunakan rubik penilaian, sehingga nilai yang diberikan berupa deskriptif.

2. Peserta didik yang diteliti adalah siswa kelas 1 yag berjumlah 7 siswa terdiri dari enam putri dan satu putra yang dikategorikan masih memiliki sisa pendengaran. Karakteristik yang dimiliki dari segi intlegensi sama dengan anak normal anak tidak mengalami hambatan dalam penglhatan dan motorik, yang mengalami hambatan hanya yang bersifat verbal. Ketrampilan bahasa siswa yaitu kosakata yang dimiliki sedikit, sulit memahami kalimat abstrak serta kurang memahami irama dan gerak. Dilihat dari karakteristik emosi dan sosial siswa kelas 1 memiliki ego dan cenderung ingin benar dalam pembelajaran PKPBI.

3. Tenaga pendidik yang ada di SLB N 1 Bantul merupakan guru lulusan dari SGPLB di Bandung dan sudah perpengalaman mengajar mata pelajaran PKPBI selama 35 tahun, sehingga guru dinilai mampu dan berkompetensi dalam mengajar mata pelajaran PKPBI.

4. Penggunaan media dalam pelaksanaan program pembelajaran PKPBI kelas 1 tahap Identifikasi disesuaikan dengan tujuan dan materi yang diidentifikasi. Media yang digunakan dalam latihan mengidentifikasi adalah tabur, tambur merupakan alat musik yang berbentuk bulat cara menggunkannya ditabuh, yang digunakan untuk mengidentifikasi suku kata

\section{Saran}

Berdasarkan hasil penelitian dan pembahasan yang telah dilakukan maka peneliti mengemukakan saran sebagai berikut:

1. Bagi Sekolah

Mengingat pentingnya program pembelajaran bina komunikasi persepsi bunyi dan irama hal ini di harapkan agar latihan PKPBI tidak hanya diberikan tidak hanya saat pembelajaran program PKPBI saja namun program juga diajarkan di dalam setiap pembelajaran di dalam kelas, sehingga kemampuan berkomunikasi dan mempersepsi bunyi anak tunarungu dapat dilatih secara optimal.

2. Bagi Guru

Guru diharapkan tidak hanya menggunakan alat musik tambur sebagai alat untuk mengidentifikasi bunyi, guru dapat menggunakan sumber bunyi lain yang ada di dalam ruangan.

\section{DAFTAR PUSTAKA}

Agustinova, D.E (2015) Memahami Metode Penelitian Kualitatif. Yogyakarta: Calpulis

Amironto \& Daryanto (2013) Evaluasi dan Penilaian Pembelajaran Kurikulum 2013. Yogyakarta: Gava Media

Arikunto. (2007). Manajemen Penelitian. Jakarta: Rineka Cipta.

Hermanto. 2010. Membangun Kesadaran Bunyi Anak Tunarungu melalui Pembelajaran Bina Komunikasi Persepsi Bunyi dan Irama di Sekolah. Jurnal UNY (online). Diaksesdarihttp://staff.uny.ac.id/sites/default/ files/penelitian/Hermanto. Pada tanggal 12 Januari 2018 jam 20.41 WIB.

Majid. (2006). Perencanaan Pembelajaran Mengembangkan Standar Kompetensi Guru. Bandung: Remaja Rosdakarya.

Kemendikbud (2016) Penelitian Program Pendidikan Khusus. Jakarta: Kementrian Pendidikan dan Kebudayaan

Suharsaputra, U. (2012) Metode Penelitian Kualitatif, Kuantitatif dan Tindakan. Bandung: Rafika Aditama 


\section{J PK (J urnal Pendidikan Khusus), 14 (1), 2018 - 25}

Mila Ayu Setyaningsih, Rafika Rahmawati

Wasita. (2012). Seluk Beluk Tunarungu dan Tunawicara. Jogjakarta: Javalitera.

Winarsih, M. (2007). Intervensi Dini Bagi Anak Tunarungu dalam Pemerolehan Bahasa. Departemen Pendidikan dan Kebudayaan. Direktorat Jenderal Pendidikan Tinggi. Direktorat Ketenagaan Yaumi, M. (2013) Prinsip-Prinsip Desain Pembelajaran. Jakarta: Kencana Media.

Yuwati. (2000). Pedoman Guru Pengajaran Bina Persepsi Bunyi dan Irama untuk Anak Tunarungu. Jakarta: Depdiknas. 